Halses etwa so lang wie die Augen. Halsschild nicht ganz so lang wie breit, so breit wie eine einzelne Flügeldecke in ihrer Mitte, herzförmig, sehr spärlich grob punktiert, gewölbt, die Wölbung bis zu der sehr feinen Randkante reichend, Hinterwinkel stumpf, Flügeldecken breit elliptisch, flach gewölbt, mit groben Punktstreifen und einer ebenso starken Punktreihe auf den Zwischenräumen; der äusserste schmale Zwischenraum und die Epipleuren rotbraun, manchmal ist auch eine rostbraune $\mathrm{Hu}$ meralmakel vorhanden. Der 3. Seitenstreifen biegt sich nicht (wie bei fast allen anderen Cymindis-Arten) hinten nach innen und verbindet sich nicht mit dem apikalen Porenpunkte des 3. Zwischenraumes. L. $7.5-9 \mathrm{~mm}$. - S üd-Transbaikalien, Nördliche Mongolei, im Quellgebiet des Irkut. - pilosissima Reitt.

\title{
Formanekia, ein neues Genus der Brachyderini. (Col. Curcul.)
}

Von Dr. Anton Fleischer in Brünn.

Formanekia n. gen.

Rüssel dick, etwa so lang wie der Kopt und so breit wie die Stirne zwischen den kurz ovalen, schwach gewölbten Augen. Fühlerfurchen vollständig, halbkreisförmig, an den Seiten des Rüssels gelegen, knapp vor den Augen nach abwärts gebogen. Scheitel kurz. Fühlerschaft die Mitte der Augen erreichend, kürzer als die siebengliedrige Geissel. Halsschild quer, so breit wie die Basis der Flügeldecken, an den Seiten des Vorderrandes unbewimpert, ohne Augenlappen. Schildchen nicht sichtbar. Flügeldecken etwas gestreckt, hinter der schmalkantig erhobenen Basis eingeschnürt, ohne vortretende Schultern. Vorderbeine viel stärker entwickelt als wie die anderen, die Innenseite aller Schienen gekörnt und beborstet. Tarsen kürzer als die Schienen, Klauen an der Basis verwachsen. Durch die hinter der schmalkantig erhobenen Basis eingeschnürten Flügeldecken und die auf der Innenseite gekörnten Schienen von allen Gattungen der Tribus Brachyderini verschieden. 


\section{Formanekia sibirica n. sp.}

Dunkelbraun, die Fühler mit Ausnahme der Keule und die Tarsen rotbraun, der Körper mit kleinen, runden, dicht anschliessenden aschgrau und schmutzigweiss gefärbten Schuppen bedeckt, und auf dem Vorderkörper überdies mit kurzen, auf den Flügeldecken doppelt längeren, abstehenden, in einfachen Reihen gestellten, hellen Börstchen besetzt. Der Rüssel wenig, aber deutlich länger als breit, parallelseitig, der Rücken flach, mit einem kurzen Mittelkielchen an der Spitze und mit einer mehr weniger deutlichen, bis auf die flache Stirn reichenden Mittelfurche. Die Augen kurz oval, wenig länger als die Schläfen, schwach gewölbt, unbedeutend vorragend. Die Fühler bis zur Mitte des Halsschildes reichend, an der Spitze plötzlich beulenförmig verdickt, das erste verdickte Geisselglied wenig länger als das gestreckte zweite, die übrigen unbedeutend breiter als lang, gegen die kräftige abgesetzte Keule an Breite wenig zunehmend. Der Halsschild etwa um ein Viertel breiter als lang, der Quere nach gewölbt, in der Mitte am breitesten, zu dem schief nach unten abgestutzten Vorderrande stärker verengt als zu der geraden, leichteingeschnürten Basis, mit grösseren flachen, pupillierten und einfachen kleinen Körnern dicht besetzt. Die Flügeldecken etwas gestreckt eiförmig, beim $\sigma^{\top}$ auffallend schmäler, hinter der gerade abgestutzten, schmalkantig erhobenen Basis eingeschnürt, in den mässig starken Streifen in dichter Anreihung punktiert, die Zwischenräume flach gewölbt. Die Beine kräftig, die vorderen viel stärker entwickelt, die Schenkel mässig gekeult, die Vorderschienen gekrümmt, auf der Innenseite gekörnt und beborstet, das erste Tarsenglied gestreckt, das zweite kürzer, das dritte stark quer, bis zur Basis gespalten, die Klauen an der Basis verwachsen.

Long: $3.8-5 \mathrm{~mm}$. Berezovka, Ussurisk, Sibirien; nach der Anzahl der eingeschickten Exemplare dort nicht selten. 


\section{$2 \mathrm{BHL}$ Biodiversity Heritage Library}

Fleischer, Antonin. 1923. "Formanekia, ein neues Genus der Brachyderini (Col. Curcul.)." Wiener entomologische Zeitung 40, 15-16.

https://doi.org/10.5962/bhl.part.2577.

View This Item Online: $\underline{\text { https://www.biodiversitylibrary.org/item/43768 }}$

DOI: https://doi.org/10.5962/bhl.part.2577

Permalink: https://www.biodiversitylibrary.org/partpdf/2577

\section{Holding Institution}

Smithsonian Libraries

\section{Sponsored by}

Smithsonian

\section{Copyright \& Reuse}

Copyright Status: NOT_IN_COPYRIGHT

This document was created from content at the Biodiversity Heritage Library, the world's largest open access digital library for biodiversity literature and archives. Visit BHL at https://www.biodiversitylibrary.org. 